\title{
Bioanalysis
}

\section{Liquid scintillation counting: how has it advanced over the years and what does the future hold?}

\author{
"Clearly, the process of liquid scintillation counting is now an established and \\ mature technique."
}

Keywords: developments $\bullet$ future $\bullet$ limitations $\bullet$ liquid scintillation counting

\section{Preamble}

Liquid scintillation counting is a technique that can be used in a production-type environment as well as research. Examples would be contract research organizations, the nuclear industry, universities and pharmaceutical companies. This article will concentrate on developments that have taken place in the instrumentation for automatic liquid scintillation counting, when counting discrete vials and flow systems. In almost all cases the isotopes in use were tritium, carbon 14, sulfur 35 and phosphorus 32. Any developments in other isotopes will not be covered.

\section{Radiotracers}

The use of radiotracers in bioanalysis is well established [1-7]. Radiochemists radio-label compounds that may be metabolized by tissue. The absorption, distribution, metabolism and excretion of the radioactivity, and hence the compound in question may be traced accurately and quantified. This is particularly useful in drug development as the radioactivity has little or no effect on the metabolism of the compound. Increasingly studies undertaken on cells rather than animals take place with radio-labeled compounds.

\section{Short history of scintillation counters}

The history of the development of liquid scintillation instrumentation started commercially in 1953 with a liquid scintillation counter by Packard Instrument Company, named the Tri-Carb 314. Since then many companies have entered the field of automatic liquid scintillation counters, including Nuclear Chicago, Beckman Instruments, Intertechnique, Kontron Nuclear Chicago, Wallac and Phillips. Perkin Elmer entered the field by taking over Wallac and subsequently Packard Bioscience. Hidex entered in 1993 and Aloka are a company producing a counter in Japan not often seen in Europe [8]. However, the situation at present is that Perkin Elmer manufactures the Tri-Carb series of counters, Hidex manufactures the 300SL [9] series and Aloka the LB-5.

The Tri-Carb series uses a detector system of two photomultiplier tubes in coincidence surrounded by a lead shield. This was a standard configuration and used by most manufacturers. The detection system, vial delivery system and size of counter have largely remained the same since inception. It has proved to be a successful and reliable system, and has become the counter of choice in many environments that require high throughput aligned with ease of use.

Since the inception of commercial liquid scintillation counters, manufacturers have endeavored to produce systems that exhibit low levels of radioactivity background. Initially this was done with lead shielding and temperature control, but later with electronic techniques which were able to identify background radioactive events from actual radioactive events which were due to the sample. The Tri-Carb series in 1987 produced the 2000CA series which used a technique called time-resolved counting which significantly lowered background, particularly for normal use counters [10].

\section{Simon Temple}

DPM Solutions Ltd, Unit 1, Dunston Technology Park, Millennium Way, Chesterfield, S41 8ND, UK

simon.temple@dpmsolutions-web.co.uk 
In 1985, Wallac Oy of Finland produced a low background level counter called the Quantulus which uses a guard detection system to lower background. Packard introduced a Tri-Carb with a guard detector in the early 1990s. Both Wallac and Packard have been acquired by Perkin Elmer and apart from software changes, the fundamental design of the counters has not altered.

\section{Recent developments}

Since the 1980s there have not been any significant developments of liquid scintillation counters until the launch of Hidex 300 SL in 2008 [9]. The Hidex 300 $\mathrm{SL}$ is a new generation automatic counter with a small footprint and a different design to the conventional coincidence counter based on two photomultipliers.

The 300 SL utilizes three photomultipliers aligned at $120^{\circ}$ from each other. Optimum detection geometry yields exceptionally high counting efficiency and counting of samples in triple mode without risk of background luminescence interference. Three photomultipliers also enable triple to double coincidence ratio counting (TDCR), which is an absolute counting method for obtaining counting efficiency of the samples without external or internal standard sources. Unlike external standard methods, TDCR is a universal method applicable for both chemical and color quenching, for aqueous and organic samples, and for different cocktails and range of isotopes. TDCR method can be used not only for counting of typical $\beta$ isotopes but also for absolute activity determination of Cerenkov radiation, for example, from Y-/Sr-90. TDCR has been used by many regulatory organizations where locally produced counters have been developed. Hidex is the first company to produce a commercially available instrument.

\section{Scintillation flow systems}

Systems that are designed to measure the flow of sample rather than a discrete sample have been in production for many years and the basic principle of measuring the signal with two photomultipliers around some form of flow cell is nothing new. Flow systems have always been a compromise between sensitivity and resolution. Most systems are connected to HPLC units and as such peak resolution is considered to be important. However, sensitivity is also an important factor, and it is difficult to achieve both. Fractions based on time may be collected from the chromatography process and then counted by a liquid scintillation counter off line. The data are then entered in a software package that will produce the chromatogram. Counting off line takes longer and so systems have been developed to optimize sensitivity and resolution without the need to collect fractions.
LabLogic Systems Limited recently introduced a system for the $\beta$-Ram ${ }^{\circledR}$ radio-HPLC detection system called Active Counting Mode (ACM $\left.{ }^{\mathrm{TM}}\right)$ [1] in an effort to improve resolution and peak definition. ACM optimizes the scintillant flow rate following the detection of a peak, usually by increasing the flow of scintillant and hence improving the counting efficiency of the peak in the flow cell. This is similar to systems such as LCARC $^{\text {TM }}[12,13]$ and SoFie ${ }^{\mathrm{TM}}$ that control the HPLC and flow detector, and stop the flow in the cell so that it may be counted in the same way as if in a scintillation counter (i.e., taking the place of the fraction collector and improving the counting statistics). These are essentially software-controlled methods of increasing sensitivity while attempting to minimize loss of resolution.

Fundamental changes in instrument design have been limited with most of the attention being given to improvements in analysis of the data and other software enhancements. However, in 2007 raytest Isotopenmessgeraete $\mathrm{GmbH}$ produced a detector, MiraStar, which utilizes four detector banks measuring, in turn, the flow stream containing the sample. The signal from each detector bank is added to give a composite of all the detector signals. This may allow better sensitivity without compromising on resolution of the peaks and uses little software influence. Initially the system used half inch photomultipliers and was intended for microflow HPLC systems, but a recent development is the Ramona Quattro which uses 111/8 detector size photomultipliers. This has improved sensitivity without compromising on resolution but still does not approach the performance of collecting fractions and counting on a plate scintillation counter such as the TopCount $[12,13]$.

\section{What does the future hold?}

Where does development of liquid scintillation systems proceed from the present? Clearly, the process of liquid scintillation counting is now an established and mature technique. Increasingly, the costs of handling and disposal of radioactivity have encouraged the market place to look for replacement of these systems. Nevertheless in absorption, distribution, metabolism and excretion studies and other applications in the cellular field, where radioactivity is used as a tracer, the level of sensitivity that may be achieved will ensure that liquid scintillation counting will always have a place. However, it would appear that there is not much encouragement for companies to invest in new instrumentation as the market is well established. It is difficult to visualize future developments that are revolutionary.

Financial \& competing interests disclosure

STemple is Director of DPM Solutions Ltd, which provides training on liquid scintillation including Tri-Carb systems manufactured by 
Perkin Elmer. S Temple is Director of Isotech Services Ltd, which provides third party service on laboratory instrumentation including Perkin Elmer manufacture. He is a Consultant to Diagnostic Imaging Ltd distributors of raytest Isotopenmessgeraete. He is employed by Meridian Biotechnologies Ltd, which manufactures and distributes scintillation cocktail and accessories. The author

\section{References}

1 Dulcino J, Bosco R, Verly WG, Maisin JR. Assay of tritium and carbon-14 in animal tissues by liquid scintillation. Clin. Chim. Acta 8(1), 58-65 (1963).

2 Mahin DT, Lofberg RT. A simplified method of sample preparation for determination of tritium, carbon-14, or sulfur-35 in blood or tissue by liquid scintillation counting. Anal. Biochem. 16(3), 500-509 (1966).

3 Renzulli C, Nash M, Wright $\mathrm{M}$ et al. Drug metabolism and disposition, disposition and metabolism of $\left[{ }^{14} \mathrm{C}\right] \mathrm{SB}-649868$, an orexin 1 and 2 receptor antagonist, in humans. Drug Metab. Dispos. 39(2), 215-227 (2011).

4 Reyes M, Hoch M, Brossard P, Wagner-Redeker W, Miraval T, Dingemanse J. Mass balance, pharmacokinetics and metabolism of the selective S1P1 receptor modulator ponesimod in humans. Xenobiotica 45(2), 139-149 (2015).

5 Abel S, Russell D, Whitlock LA, Ridgway CE, Nedderman AN, Walker CK. Assessment of the absorption, metabolism and absolute bioavailability of maraviroc in healthy male subjects. Br. J. Clin. Pharmacol. 65(Suppl. 1), 60-67 (2008).

6 Roberts D, Lockley B. Radiosynthesis; a vital role supporting drug development? Drug Discov. World 13, 59-64 (2004).

7 Lappin G, Temple S. Radiotracers and drug registration. In: Radiotracers in Drug Development. CRC Press, Taylor and Francis, FL, USA (2006). has no other relevant affiliations or financial involvement with any organization or entity with a financial interest in or financial conflict with the subject matter or materials discussed in the manuscript apart from those disclosed.

No writing assistance was utilized in the production of this manuscript.

8 Passo C. The evolution of liquid scintillation technique: a personal perspective. Presented at: LSC 2013. Barcelona, Spain, 17-22 March 2013.

9 Eikenberg J, Beer $\mathrm{H}$, Jäggi $\mathrm{M}$. Determination of ${ }^{210} \mathrm{~Pb}$ and ${ }^{226} \mathrm{Ra} /{ }^{228} \mathrm{Ra}$ in continental water using HIDEX 300 SL LSSpectrometer with TDCR efficiency tracing and optimized $\alpha / \beta$-discrimination. Appl. Radiat. Isot. 93, 64-69 (2014).

10 Roessler N, Valenta RJ, van Cauter S. Time-resolved liquid scintillation counting. In: Liquid Scintillation Counting and Organic Scintillators. Ross H, Noakes JE, Spaulding JD (Eds). Lewis Publishers, Inc., MI, USA, 501-511 (1991).

11 Attwood J, O’Brian B, Loaring HW, Williams A. Evaluation of active counting mode option in LabLogic $\beta$-RAM model 5 and Laura software. www.lablogic.com

12 Nassar AE, Martinet M, Parmentier Y, Lee DY. Comparison between liquid chromatography-accurate radioisotope counting and microplate scintillation counter technologies in drug metabolism studies. www.aimresearchcompany.com

13 Nassar AE, Parmentier Y, Martinet M, Lee DY. Liquid chromatography-accurate radioisotope counting and microplate scintillation counter technologies in drug metabolism studies. J. Chromatogr. Sci. 42(7), 348-353 (2004). 